\title{
Regina Marsiglia e a introdução das ciências sociais no ensino médico da Faculdade de Ciências Médicas da Santa Casa de São Paulo
}

Regina Marsiglia and the introduction of social sciences in medical education at Faculdade de Ciências Médicas

\section{da Santa Casa de São Paulo}

Selma Patti Spinelli

Faculdade de Ciências Médicas da Santa Casa de São Paulo. São Paulo, SP, Brasil.

E-mail: selmapattispinœuol.com.br

\section{Correspondência}

Centro de Estudos Augusto Leopoldo Ayrosa Galvão. Rua General Jardim, 618, Vila Buarque. São Paulo, SP, Brasil. CEP oI223-0IO.
Este texto é um marco histórico no desenvolvimento curricular do curso de medicina da Faculdade de Ciências Médicas da Santa Casa de São Paulo (FCMSCSP). Pelo seu simbolismo nas mudanças da formação médica, vale a pena contextualizá-lo, até porque Regina Marsiglia teve protagonismo impactante. Bem sabemos que a história dos homens não se faz com uma só pessoa! Porém, podemos constatar que, na história, muitas vezes, com pessoas certas nos lugares certos e a um tempo determinado para a mudança, as coisas acontecem! Permitam-me uma abordagem pessoal desta que foi testemunha e companheira de vida e trabalho.

Conheci Regina quando éramos estudantes universitárias, participando do nosso primeiro Congresso Estudantil - da União Estadual dos Estudantes de São Paulo, em Piracicaba, 1965. Regina Marsiglia concluíra seu curso de serviço social na Pontifícia Universidade Católica (PUC) de São Paulo e já se preparava para cursar ciências sociais na Universidade de São Paulo (USP). Daí trocamos nossas impressões, o que nos aproximou por toda a vida, em períodos de convivência profissional e pessoal. Ao nos interessarmos pelo campo da saúde, já tínhamos alguma experiência profissional, até que os caminhos se estreitaram no trabalho nas escolas médicas.

A educação médica passa por mudanças, sobretudo na década de 1950, quando a população brasileira reclama por mais vagas e mais escolas. Assim, entre 1968 e 1971, de 27 escolas médicas, o Brasil cria 73 cursos médicos (Donnangelo, 1972), todos eles estruturados nos moldes dos cursos tradicionais já existentes, porém sob influência de um projeto de desenvolvimento social. 
As escolas surgem com novas disciplinas e/ ou departamentos (e não mais Cátedras) que contemplavam os estudos sociais, na maioria vinculados aos departamentos de medicina preventiva, medicina social e saúde pública.

Neste âmbito, porém, vale ressaltar a experiência da Santa Casa (Hospital da Irmandade da Santa Casa de Misericórdia de São Paulo - ISCMSP) como escola médica. Foi campo de práticas das primeiras escolas tradicionais, e em 1963 passa a ter seu próprio curso de ciências médicas, mantido pela Fundação Arnaldo Vieira de Carvalho e inserido no Hospital da ISCMSP. Foi a primeira escola privada na cidade de São Paulo, constituída como Fundação. Havia ali um grupo de médicos que, além das atividades profissionais exercidas, estavam, em sua maioria, envolvidos em programas de ensino médico em outras instituições e na saúde pública, e sempre ativos nas discussões educacionais em torno da formação médica.

Entre 1963 e 1969 houve grande expansão de escolas médicas. A FCMSCSP iniciou suas atividades privilegiando modificações na estrutura curricular tradicional: tendo nascido praticamente dentro de um hospital, pôde ver aprovado um currículo bastante inovador, em que a prática se impunha nas teorias que a sustentavam. Enquanto a maioria das novas escolas já nascia de "velhas" fórmulas testadas pelas escolas tradicionais (Ciclo Básico - Ciclo Clínico), a Santa Casa logrou credenciar um currículo pleno, àquela altura bastante inovador, absorvendo os pontos relevantes das discussões didáticopedagógicas. Incorpora assim, as concepções da crítica do pensamento reformista da educação em geral que ocorreu, sobretudo, na década de 1960.

Em 1969, sob Regime Militar, o Decreto-Lei no 869/1969 do Conselho Federal de Educação fixou o currículo mínimo para todas as escolas do país, montado na fórmula tradicional - para facilitar a transferência dos filhos dos militares e demais..., com isso se verificaram "falsos" alunos, membros da repressão política (Brasil, 1969).

Importa saber que a inclusão das questões sociais num currículo acentuadamente biologizado exigia, digamos, "uma linguagem social que fosse científica". A "era do planejamento" imperava e o desenho curricular tinha por eixo e articulação em cada fase a integração pari passu das ciências sociais com a psicologia médica e as ciências físicas e biológicas, na busca ou concretização do tipo de médico que visava formar.

Esse processo, patrocinado pela Organização PanAmericana da Saúde (OPS) e pela Organização Mundial da Saúde (OMS), passou por várias fases que vitalizam o debate sobre a transformação requerida. Vale lembrar as fases de absorção dos conteúdos psicológicos e sociais para resguardar o pioneirismo da Santa Casa num modelo novo de formação médica. Naquela época, os sociólogos se encontravam para debater e criticar os recortes da sociologia como ciência autônoma, e a ideia de "ciência aplicada" era questionada, inclusive pela academia, embora não fosse o nosso caso, fato esse que fez a Regina enfrentar dificuldades para defender sua tese de doutorado pela USP (acreditem, foram 12 anos de entraves!).

Pois bem. Regina Marsiglia foi partícipe atuante em cada fase, e em todas as modificações posteriores, quando outras mudanças viriam, desde quando participava como assistente social das discussões de "casos médicos elucidativos, escolhidos" até 2017, como docente de mestrado e doutorado, participando em 300 bancas de defesa da área de ciências sociais em saúde. Apresento sumariamente algumas dessas fases:

Primeira fase (1963/1964): o curso de medicina criado em 1963 estruturou-se em departamentos (Brasil, 1962) e cabe ao Departamento de Medicina Social o ensino de um elenco de matérias que vinculasse conteúdo de projetos de ação em saúde coletiva. No entanto, o enfoque do ensino dessas disciplinas era essencialmente individual, centrado no paciente como indivíduo e o médico (seja em sua relação médico-paciente, seja na sua inserção como futuro profissional liberal, que à época prevalecia como prática dominante de trabalho médico). Ao rito de "preparar o médico para o trabalho nos serviços de saúde pública”, em torno do paciente, produzia-se um estudo global (Estudo Global do Paciente - EGP), isto é, integração de aspectos clínicos, psicológicos e sociais - medicina integral. 0 âmbito dessa discussão possibilitava a articulação de três departamentos: Clínica Médica, Psicologia e Psiquiatria e Medicina Social. Equipava-se, assim, o futuro médico com um olhar "armado" em relação ao paciente, ou seja, médicos clínicos com formação em saúde pública. 
Nesta equipe, Regina Marsiglia inicia seu percurso. O conteúdo de sua visão, da moderna formação como assistente social, acrescida das ciências sociais, provoca um salto no entendimento da relação médicopaciente, invertendo a relação tradicional (sujeitoobjeto da aprendizagem). Sua formação, sua visão de mundo e seus valores, aliados à circunstância enriquecedora do trabalho em grupo, com professores conscientes de seu projeto, mas inconscientes de seu pioneirismo, transformam o processo educativo, altamente exitoso.

Na segunda fase (1965/1969), a vinculação teóricoprática cada vez mais impõe a incorporação de profissionais não médicos, já que o currículo avança na necessidade de um contato profissionalizante com o paciente. A criação de um Centro de Saúde Escola (pioneiro no curso médico) expõe os estudantes a situações da realidade complexa e demanda instrumentos teóricos para interpretá-la. O conceito da “medicina integral”, centrado na visão individual do paciente, acompanha a conjuntura de valores e conceitos, com a consciência da necessidade de uma visão global da realidade do país. Assim, os médicos professores, com visão social, agora demandam também para si os conceitos de desenvolvimento, estrutura social, produção capitalista, classes sociais e Estado e suas implicações nos serviços de saúde. Na transposição do enfoque individual do paciente, em que o social entrava na explicação como epifenômeno, para o enfoque coletivo, a sociologia oferecia um arsenal de conceitos do coletivo. Desse modo, o aluno terá a prática dos serviços completando o arcabouço teórico-prático da realidade social brasileira.

Em meio às novas críticas da situação da saúde da população e da demanda e utilização dos serviços há uma cristalização de novo papel do médico e sua capacidade de transposição da visão individual à coletiva. O Departamento de Medicina Social vai alicerçando, cada vez mais, os conteúdos sociais na formação.

Terceira fase (1970/1972): período de crise social e política no país, a qual perpassa as instituições, principalmente as formadoras. Crise nas escolas novas, que ao adentrar o ciclo clínico enfrentam as insuficiências dos "hospitais improvisados" para o ensino prático. Na Santa Casa, a integração programática dos departamentos, antes horizontal, agora persegue a integração vertical. Se a disciplina de Epidemiologia ancorava a transposição da visão individual para a coletiva, novos conteúdos para se estudar a história natural da doença se acresciam. Os estudos da História Natural do Comportamento do Doente (assim mesmo nominada) e da Antropologia Especial reforçam todo um conjunto de conceitos das ciências sociais e de conduta, e delas às ciências sociais aplicadas à medicina, influenciando outras disciplinas (Pediatria-Pediatria Social; Obstetrícia-Obstetrícia Social; Clínica Médica - Clínica de Família), tratando o social como epifenômeno da doença, exposto em temas de aula como “Aspectos Sociais da Desnutrição”. Nesse processo de reorientação e mudanças curriculares, a Regina Marsiglia atuou fortemente para dar amplitude à abordagem sociológica.

Eu também tenho lugar nessa história, quando a partir de 1974, saindo da Faculdade de Medicina do $\mathrm{ABC}$, Regina me chama para essa tarefa, como docente no Departamento de Medicina Social da FCMSCSP, na equipe de professores responsáveis pelas disciplinas História Social da Medicina, Ciências Sociais Aplicadas à Medicina e Organização dos Serviços de Saúde. A carga de sociologia no currículo, a esta altura, era bastante ampliada, porque também participávamos das discussões teórico-práticas de EGP. Reforça-se, assim, a necessidade de "traduzir" textos originais como estratégia didática, com o cuidado de não sacrificar a abordagem propriamente sociológica, ou outros modi operandi, como dispor essas publicações para os médicos residentes de medicina preventiva e social do Departamento, o que, efetivamente, causava estresse - mas alguns residentes reescreviam os textos com muita sapiência.

E aqui se destaca o texto em epígrafe. Ele é resultado do empenho e trabalho intelectual dessa equipe de professores, que por meio de estudos, reuniões e seminários selecionou conceitos básicos das ciências sociais, reescrevendo-os numa linguagem didática acessível, visando à formação na graduação e pós-graduação (nesse momento residência médica em medicina preventiva e social e/ou especialização em saúde pública). Estava surgindo toda uma literatura de sociologia na medicina, especificamente brasileira, isto é, o campo da saúde coletiva.

Destaco a participação nessa produção acadêmica de médicos residentes do Departamento de 
Medicina Social com vocação didática e interesse no aprofundamento teórico-metodológico da saúde coletiva. Rita Barradas Barata, que era, na época, médica residente e autora da redação desse texto, atuou e contribuiu ativamente nesse processo. Hoje, Rita é referência intelectual na área de epidemiologia e professora da FCMSCSP.

Agradeço o convite da revista Saúde e Sociedade pela oportunidade de preitear minha admiração a Regina Marsiglia pelo pioneirismo, a grande construtora da vertente ciências sociais em saúde coletiva. Tenho orgulho de termos trabalhado juntas, numa convivência de 43 anos. Aprendi com Regina o que é dignidade, coerência e amor à vida.

\section{Referências}

BRASIL. Decreto-lei no 869, de 12 de setembro de 1969. Dispõe sobre a inclusão da Educação Moral e Cívica como disciplina obrigatória, nas escolas de todos os graus e modalidades, dos sistemas de ensino no País, e dá outras providências. Diário Oficial da União, Brasília, 15 set. 1969. Seção 1 , p. 7769 .

BRASIL. Ministério da Educação e Cultura. Comissão de Ensino Médico. O ensino médico no Brasil: a expansão da rede escolar. Brasília, DF, 1972. (Documento 1).

DONNANGELO, M. C. F. Medicina e sociedade. São Paulo: Biblioteca Pioneira, 1972.

SPINELLI, S. P. Educação médica no contexto da educação e do mercado de trabalho. In: MARSIGLIA, R. M. G. (Org.). Ensino de graduação em saúde: ingresso e inserção profissional: FCMSCSP (19632013). São Paulo: Casa de Soluções e Editora, 2013. p. $25-52$. 